\title{
Improvement in Millipore and Implementation of Pneumatic System for Burr Removal
}

\author{
Akshay Kshatriya, Dhanraj Mane* and Rohit Patil \\ Department of Mechanical Engineering, Suman Ramesh Tulsiani Tehnical Campus Faculty of Engineering Khamshet Pune(Maharashtra). India \\ Received 18 Feb 2018, Accepted 21 April 2018, Available online 27 April 2018, Vol.8, No.2 (March/April 2018)
}

\begin{abstract}
Each component or a part which is nature or arranged by human has an end period or disillusionment time. We as masters influence an average endeavor to find the life to time and make various arrangements to diminish the failure and augmentation the life time. Machining is improved the situation screws, Cylinder heads, Cylinder block, crank cases, cover cases and crank \& Main Bearing (MB) Caps. Throwing is improved the situation cam shafts and motor external bodies. Every part component has a remarkable request of handling. It takes after and request of either throwing or manufacturing and machining. Furthermore, in view of the tainting in the motor, the motor keeps running with a considerable measure of issues like wear \& tear, Huge clamor, Friction, Vibration and so on, of interior parts of the motor. These burrs are the main consideration for the sullying caused in the motor get together. Because of this client disappointment is going high. To control this specific strategy are taken after and kept up.
\end{abstract}

Keywords: Main bearing, Cylinder heads, Burr, Failure, Machining, Cylinder block

\section{Introduction}

Cleaning and degreasing metal, plastic and glass by plunging, splashing or showering with fluid cleaners is a typical procedure in the assembling business. Mechanical parts washers expel oil, soil, oil rough tidy, erosion, and different contaminants from the surface of segments underway. The parts washers are generally controlled by power, gas, oil, or steam and incorporate a wash tank made of glass, plastic, steel, or stainless steel.

Compacted air devices are obviously ordinary on manufacturing plant floors, and to specialists a packed compressed air firearm might be the speediest and most advantageous strategy for cleaning themselves down. Numerous organizations will have composed safe work systems that blueprint how to play out an errand with least hazard to individuals, gear, materials, condition and procedures. Due to this most workers are very much aware that utilizing compacted air spouts to expel flotsam and jetsam.

The motor square is the primary structure of a motor that backings and keeps up the arrangement of inward and outer segments. The motor square comprises of barrel piece and Crankcase. The barrel piece is one of your motor's focal segments. It assumes a key part in the oil, temperature control and steadiness of the motor and it must be of most elevated

*Corresponding author's ORCID ID: 0000-0002-7676-0781 DOI: https://doi.org/10.14741/ijcet/v.8.2.38 quality so there will be no disappointment or sullying Burrs in the chamber piece are mind boggling and troublesome issues. They require extra completing activities and confuse get together and in addition chance harm to the part. Aside from the burr shaped amid machining forms there are distinctive contaminants which diminishes the execution of the motor. Consequently, to assess these contaminants Millipore test is done. So as to diminish these contaminants on the Main Bearing (MB) caps, a industrial washer is utilized. By utilizing the pneumatic framework and presenting extraordinary course of action of the spouts in clothes washer, proposals issues can be lessened.

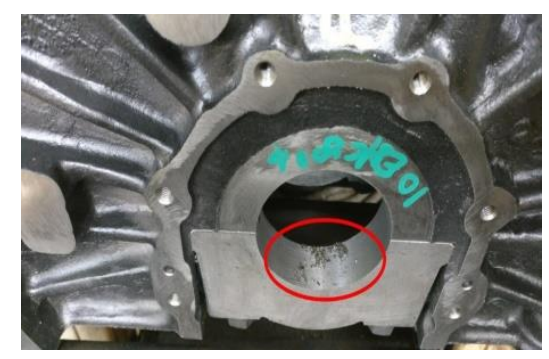

Fig.1 Detection of Burr

\section{Literature Review}

Hieu Nguyen (April 8, 2005) revealed in his study of Manufacturing Processes and Engineering Materials 
Used in Automotive Engine Blocks that cast iron and aluminum combinations have been the special materials used to produce most diesel and regular gas fueled motor squares. Be that as it may, with a more noteworthy accentuation on expanding the proficiency of the motor by means of weight decrease, makers have started to search for elective composites that are lighter than cast iron and aluminum alloys, while holding the fundamental quality to withstand the powers of a motor. In his work, the practical necessities of the motor piece, the procedures used to make the part, and the mechanical properties of the amalgams are examined.

D.A. Green and R. Lewis (May 20, 2008) revealed in their study of the effects of soot-contaminated engine oil on wear and friction that soot-contaminated lubricant has been appeared to deliver huge measures of motor wear. The paper additionally talks about ash arrangement and its general impacts inside the motor (counting grinding and proficiency), and different issues including filtration or evacuation, consequences for the oil, motor outline and task, and future industry targets and innovations related to soot contamination.

William M. Needelman and Puliyur V. Madhavan (November 7, 1988) revealed in their review of lubricant contamination and diesel engine wear that due to the high levels of strong polluting influences found in motor oil, and new advancements for controlling these materials, accentuation is set on particulate contamination.

Jan C. Aurich and David Dornfeld (April 3, 2009) revealed in their study of burrs-analysis, control and removal incorporates a discourse of burrs in ordinary machining, process getting ready for burr minimizationand additionally micromachining applications.

Md. Raquibul Hasan (March 1, 2017) revealed in their study of failure investigation report on different components of an automotive engine that the failure of every part having an indistinguishable explanation behind its failure. Along these lines it influenced the execution of the vehicle and it is extremely costly for the client to substitute the harmed parts for a few times. In this paper, we displayed point by point examination of the foundations for the failure alongside preventive proposal to keep up the motor for better execution.

K. Vinoth Kumar, R. Siva Sankar and M. Raghul revealed in their study of reduction of engine contamination and improvements in engine efficiency that at the point when a segment at definite stage requires some no. of machining activities performed, which prompts arrangement of burrs. These burrs get settled somewhere within the parts like openings, holes or underneath of the machining region. At the point when motor is collected and oil is circled, they get off from that point and move to the moving region like cylinder and barrel head and piece, Crank case, Cam shaft and so forth. At the point when motor runs they make the wear and tear of material. Contamination and Aesthetics are the major issues looked in late patterns in the vehicle. To lessen this impacts and issues, an examination has been made and the issues are investigated with suitable strategies. Consequently, different ideal arrangements are inferred and are actualized to accomplish the greatest effectiveness and efficiency of the engine.

\section{Methodology}

The problem in the cylinder block was due to the following reasons:

- Increased Millipore value of the MB caps present in the cylinder block.

- Improper removals of the burr from the inner surfaces of the cylinder block which caused various defects.

1) Increased Millipore value of the MB caps present in the cylinder block

It was found that, out of the total contaminants present on the surface of the MB caps about 50-70\% contaminants were in the inner surface of the bore of the MB caps. Designing of this nozzle plate helped in proper cleaning of the MB caps, which decreases overall contamination in the cylinder block. The figure below shows the geometry of the nozzle plate.

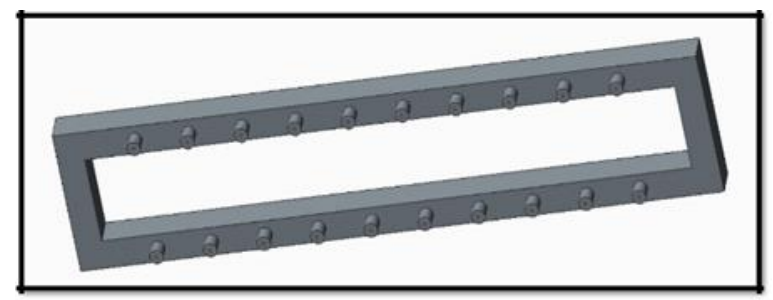

Fig.2 Geometry of Designed Nozzle Plate (CREO 3.0)

2) Improper removals of the burr from the inner surfaces of the cylinder block which caused various defects

After the machining process in the MB caps, the burr gets deposited on the inner surface of the cylinder block. This burr remains on the inner surface and causes various defects in the cylinder block and also causes the wear and tear of the machine at the further machining process. Hence a pneumatic system was designed such that it removed majority of the burr particles on the inner surfaces which caused problems. 


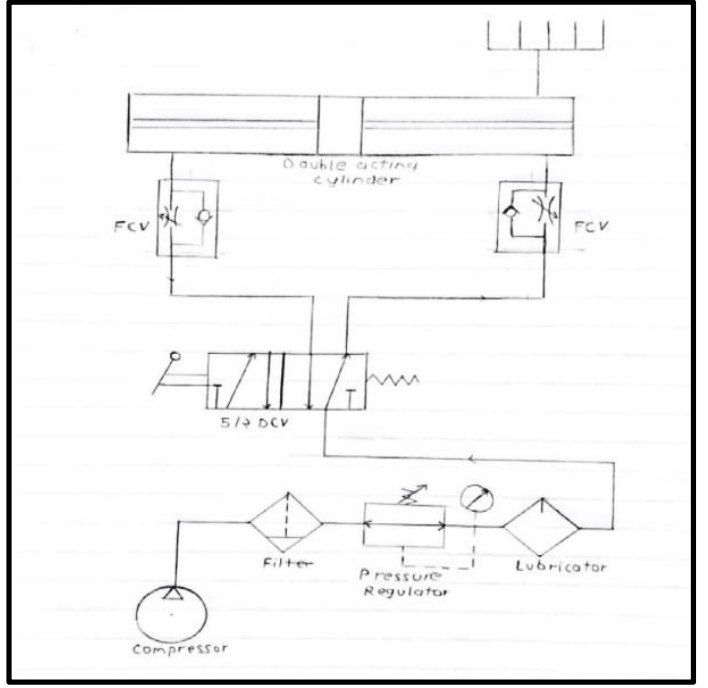

Fig.3 Pneumatic Circuit Design

\section{Result}

Initially, the Millipore value was around 55-60 mg, which was quite high according to the standards specified. Hence, resulted in washing of the caps twice to get the value within limits. This required twice the time which would be required for washing which resulted in loss of valuable time.

After improvement, there was decrease in the value of Millipore reading up to $25-30 \mathrm{mg}$ this reduced the time which was required initially.

Table 1 Reduction in Millipore Value

\begin{tabular}{|c|c|c|c|}
\hline S. & $\begin{array}{c}\text { Actual Reading } \\
\text { Needed }\end{array}$ & $\begin{array}{c}\text { Initial } \\
\text { Millipore } \\
\text { Reading }\end{array}$ & $\begin{array}{c}\text { Improved } \\
\text { Millipore } \\
\text { Reading }\end{array}$ \\
\hline 1 & $25 \mathrm{mg}$ & $55-60 \mathrm{mg}$ & $25-30 \mathrm{mg}$ \\
\hline
\end{tabular}

Initially, the burr in the cylinder block was cleaned using the air guns, which failed to reach the inner part of the cylinder block. This caused problem for the machining process at the further station.

Hence implementation of new pneumatic system cleaned the burr from the inner surface efficiently hence reduced the problem caused resulting in reduced wear rate of the tool at the further machining process.

\section{Conclusions}

To keep your industry running, you require clean parts, fuel and pressure driven liquids that are free of particles and other pollution. For very nearly 50 years, Millipore has given dependable, delicate field examining units and defilement tests that have progressed toward becoming industry Quality Control (QC) principles. Rely upon Millipore to build effectiveness and life expectancy of your intricate apparatus.
When it comes to quality, functionality, ease of operation and smooth, clean contacts, having industrial parts deburred is of paramount importance. Even the slightest imperfections will cause parts to wear faster, and eventually create breakdowns that reduce the effective lives of the machinery they are a part of.

Accelerated machine wear and tear is just one reason it is so important for parts to be deburred. Rough edges on industrial parts can cause them to catch in unexpected places, which in turn can cause accidents leading to unnecessary injury.

Best case scenarios of incidents caused by nondeburred machinery will force costly delays in productivity while parts are replaced. None of this tends to sit well with production line managers and workers.

While the process of deburring is often time consuming and costly, it is an effective process that is usually required in order to save both time and money later on in the industrial process. Putting in the extra finishing time initially usually pays for itself many times over at the end of the day.

The value of the Millipore which was around 50mg was reduced to $25 \mathrm{mg}$ which was in the standard prescribed limits.

Also the pneumatic system cleaned the burr particles from the inner surfaces resulting in cleaner production. Also the system reduced the cleaning time of the block and reduced the manual work up to some extent.

\section{References}

Hieu Nguyen, (2005), Manufacturing Processes and Engineering Materials Used in Automotive Engine Blocks, School of Engineering Grand Valley State University (Term paper), 2-4.

D A Green, R Lewis, (2008), The effects of soot-contaminated engine oil on wear and friction: a review, JAUTO468 Proc IMechE Vol. 222 Part D: J. Automobile Engineering, 1-6.

William M. Needelman, Puliyur V. Madhavan, (1988), Review Of Lubricant Contamination And Diesel Engine Wear, Society of Automotive Engineers, 3-8.

Jan C. Aurich, David Dornfeld (2009), Burrs-Analysis, Control and Removal, Springer Heidelberg Dordrecht London New York, 3-9.

Md. Raquibul Hasan, (2017), Failure Investigation Report on Different Components of an Automotive Engine, International Journal of Mechanical Engineering and Applications, 48-51.

K.Vinoth Kumar, R.Siva Sankar, M.Raghul, (2006)Reduction of Engine Contamination And Improvements In Engine Efficiency, IOSR Journal of VLSI and Signal Processing, 8990. 